\title{
Transformation Mechanism of Ore Matter in the Weathering
}

\author{
Victor Bragin $^{1,2}$, Irina Baksheyeva ${ }^{1}$, Margaret Sviridova ${ }^{2}$ \\ ${ }^{1}$ Siberian Federal University, Krasnoyarsk, Russia \\ ${ }^{2}$ Institute of Chemistry and Chemical Technology of Siberian Branch \\ of Russian Academy of Sciences, Krasnoyarsk, Russia \\ Email: Irina_igorevna@mail.ru
}

Received August 31, 2012; revised October 2, 2012; accepted October 10, 2012

\begin{abstract}
Grain-size class redistribution of non-ferrous, precious metals and iron in copper-nickel ores tailings from Norilsk industrial region was after artificial weathering investigated. Possible mechanisms of metal redistribution were suggested.
\end{abstract}

Keywords: Technogenic Raw Materials; Cu-Ni Ores; Nonferrous and Precious Metals; Iron; Platinum Group Elements; Grain-Size Class Redistribution of Metals; Redistribution Mechanisms

\section{Introduction}

The process of non-ferrous and precious metals extracting from the tails is an essential reserve for non-ferrous industry in old mining areas. Ecologically, development of technology is important too. Solution of the problem is particularly urgent in reference to highly oxidized tails, as metal extraction technology for them is quite undeveloped, and, besides, their ecological effect is significant.

Current approaches to the problem of old tails are usually considered technologically and ecologically. There are a great number of researches and practical works describing old tails as a potential source of metal. In this case, the major scientific and engineering problem is the optimization of reextraction methods. One of the latest researches in the field has been done by V. A. Chanturiya and V. Ye. Vigdergauz [1,2]. On the whole, available results show that a non-ferrous, precious metals extraction rate reduces significantly due to the increase of weathering. The principal mechanisms which affect technological properties are the following: oxidation of sulphide minerals surfaces, formation of secondary mineral phases (which are normally slime with a low contrast of precious metals distribution) and adverse movement in the composition of pulp liquid phase. In some cases, when the increase of weathering is considerable, it is possible to extract metals-zinc, copper, nickel-by using hydrometallurgical methods. It can be done only if sulphide matrix is nearly completely decomposed and, thus, soluble forms of non-ferrous metals and a favorable composition of barren rock generate.
During the recent 10 - 15 years much attention has been paid to the ecological aspect in the old tails research. The major studies have been carried out on the materials from old mining areas in Europe and North America [37]. In Russia research in the field was done by D. V. Makarov $[8,9]$. The research was mainly devoted to the problems of transformation of primary minerals (both ore and non-metallic ones) into secondary mobile forms, which can be especially dangerous for the environment. There have been developed a few methods in order to reduce the ecological impact of oxidized tails. They include measures aimed at oxidation preventing or slowing down and building up in drainage lines which transfer toxic mineralized waters. There are also designs of geochemical barriers made of natural calcium carbonate for getting commercial products out of drainage waters.

The problems of precious metals reextraction have been given much less consideration due to a fewer number of such objects, which thus resulted in a fewer ecological problems and the less total reextraction value. Besides, technically the objects are difficult to research. The most well-known work, researching gold behavior in anthropogenic formations on the territory of Krasnoyarsk region and Khakassia, were carried out by V. A. Makarov Reextraction of platinum and platinum metals from anthropogenic products of Norilsk region were studied and described by a group of scientists, Yu. V. Blagodatin and D. A. Dodin among them [10]. The data concerning behavior and technological properties of platinoids are quite important as the platinum extraction anthropogenic products within Norilsk industrial area is expected to increase and reach $10 \%$ out of total output. In general, the 
research results prove a particular complexity of the problem. Modern technologies make it possible to extract free forms of precious metals of gravity size. However, the most common metal forms are unexposed impregnation, isomorphic component of both metallic and nonmetallic minerals, loose grains of micron and submicron grade-size. Thus the traditional approach cannot be used. Moreover, the process becomes more complicated due to the presence of various secondary forms of non-ferrous metals in the tails. Consequently, there is no universal method for simultaneous extraction of non-ferrous and precious metals from old tails.

The solution of the problem can be found in terms of the approach, based on the mechanism of ore material transformation when being weathered. The approach could use the mechanism in order to control a hypergene process for the formation of material constitution, which could be used optimally while reextracting valuable constituent from tails. We suppose that low efficiency of process solutions of the problem is caused by the lack of knowledge about how precious metals are redistributed in different phases during weathering and also about the correlation between the redistribution and phase transformations of non-ferrous and rock-forming metals. Detailed analysis of the processes could control their rate, choose conditions, when characteristics of precious metals distribution are optimal for their simultaneous extraction with non ferrous metals.

The most important process, which determines formation of technological properties of weathered coppernickel tails, is redistribution of platinum, platinum metals and gold within different mineral phases and grain-size classes, caused by sulphide oxidation. The phenolmenon is described generally, considering the case of oxidation zones in sulphide deposits. However, specific mechanisms, concerning raw materials from Norilsk industrial hub, are unknown. In order to study the mechanisms, there have been conducted experiments with artificial weathering of anthropogenic materials samples.

\section{Materials and Methods}

The study conducted in the Institute of Chemistry and Chemical Technology of SB RAS was founded in 2004. Tails from the Norilsk region were put to weathering simulate in the laboratory in an evaporating mode. The material was being kept humid by adding distilled water regularly. The experiment was determining the tails granulometric composition and grain-size class redistribution. Solid samples were taken in 6 months, 1 year and 4 years since the experiment beginning. Screen test was done according to a wet scheme, followed by check dry screening. The content of precious and non-ferrous metals in the samples was determined by mass-spectrometric [11] method after opening with the help of chloroazotic acid according to the standard scheme. As for the nonferrous metals, in addition, atomic absorption method was used after the nitric opening. The application of mass spectrometric analysis in the research made it possible to obtain the information about the distribution of all periodic table elements according to both grain-size class of weathered tails.

\section{Results and Discussion}

The carried out research enabled to reveal a number of characteristics in the precious metals behavior after the weathering of copper-nickel tails. It is determined that during weathering of sulphide minerals of copper nickel ores tails in Norilsk industrial hub, dispersive impregnation of precious metals opens up at the rate which is higher than the one of sulphide matrix oxidation. Besides it is followed by transition of platinum and palladium into slime with the grain-size of less than $0.044 \mathrm{~mm}$ (Figure 1). There have been found the association of opened up dispersive particles of precious metals with secondary iron-oxide materials.

Concentration of non-ferrous metals (copper and iron) after weathering is situated in class $-0.044 \mathrm{~mm}$, in which oxide phase dominate according to X-ray phase analysis and microscopic observation. Furthermore, as Figure 1 demonstrates, the growth of the metals can be seen in grain-size classes of about $0.1 \mathrm{~mm}$, which are typical of sulphide minerals, having been subjected to partial oxidation on the surface. The most interesting observations can be done when comparing the behavior of precious metals (platinum and palladium). While palladium is being redistributed similarly to iron (with the growth both in slime and sand fraction of $0.1 \mathrm{~mm}$ ), platinum contrariwise is transferring from the materials into slime. Moreover, platinum redistribution from sand classes into slime is much more considerable, than that of iron, copper and palladium and tails material as well generally: platinum density of distribution grows by as 5 times as much as compared to initial density (Figure 2). Thus, after weathering there is separation of platinum and palladium flows, platinum looses faster, being drawn to iron-oxide slime phases, whereas palladium tends to have the primary associations with iron and non-ferrous metals.

The revealed features can be explained considering the differences in platinum and palladium forms which occur in primary sulphides. It is well known, that in Norilsk deposits ores platinum and palladium associate closely with sulphide minerals. However, platinum is represented mainly as thin impregnations of independent phases, whereas palladium occurs as isomorphic admixture. Regarding the latter, the revealed feature is easy to explain. Sulphide matrix corrosion on the surface of intergrowth with platinum mineral causes loosing and pitting of plati 


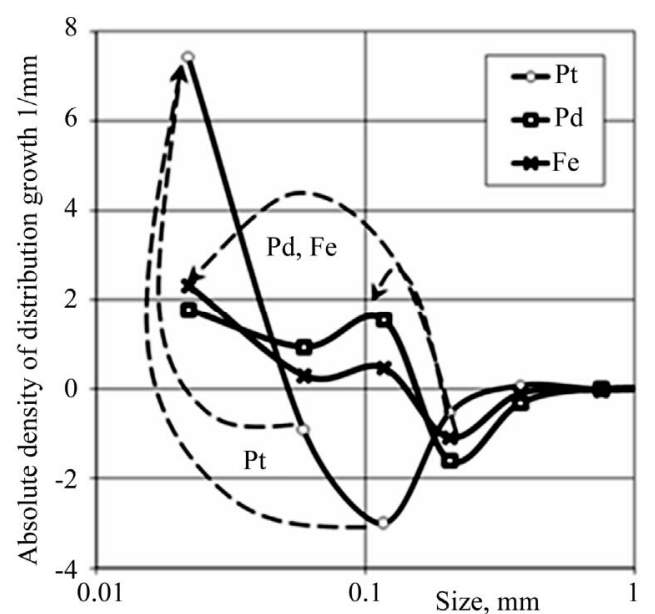

Figure 1. Grain-size class redistribution of platinum, palladium and iron after a storage period of 4 years.

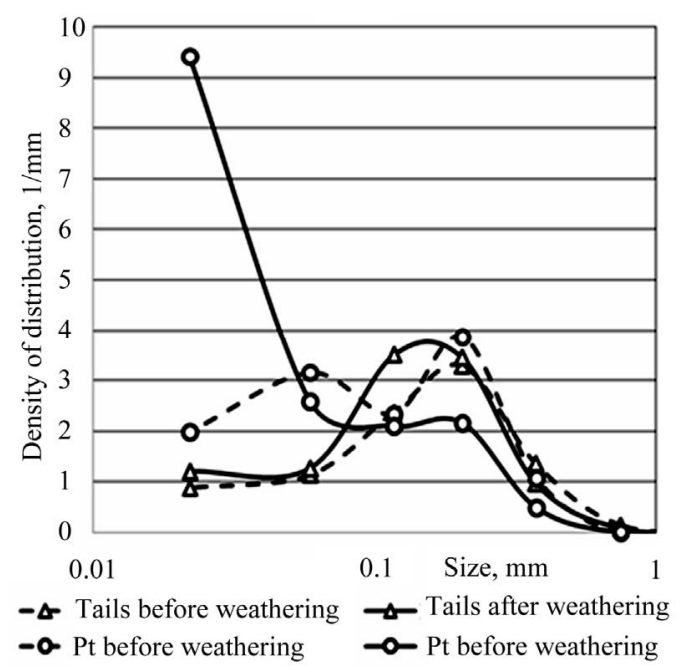

Figure 2. Grain-size class redistribution of tails material and platinum.

num grains. In this case, catalytic properties of platinum could are important. If impregnation size is quite big (less than 5 - 10 microns), it is slime, where platinum accumulates. At the same loosing of isomorphic associated palladium is impossible without compete matrix destruction, Therefore, the metal growth after weathering can be observed both in slimes with iron-oxides and nonferrous metals oxides and in grain-size class of about 0.1 $\mathrm{mm}$ ( where sulfide grains, having been partially oxidized on the surface, concentrate, they still contain palladium as isomorphic admixture. Revealed features of platinum and palladium redistribution after weathering are of significant interest for establishing the technology of precious metals extraction from old nickel-copper tails. Separation of platinum and palladium flows, with platinum being loosed and separated from the bulk of sulphides, gives interesting opportunities in developing com- bined schemes of anthropogenic material processing on the territory of Norilsk region.

\section{Conclusions}

The redistribution of non-ferrous and precious metals in copper-nickel ores tailings after artificial weathering was investigated. Possible mechanisms of metal redistribution have been discussed. On basis of obtained data, processes mechanisms were suggested.

There were found essential distinctions in the behavior of platinum and palladium caused by the difference in their forms occurring in primary sulphides. It should be noted, that redistribution of palladium (occurring mainly as isomorphic admixture in primary sulphides) after weathering is simultaneous to the redistribution of iron and non-ferrous metals, which are associated with sulphide and iron-oxide phases. In contrast to that, redistribution of platinum (occurring mainly as dispersive impregnation in primary sulphides) goes at a higher rate; platinum accumulates in slime fractions in association with ironoxide secondary phases. It is assumed that accelerated platinum loosing can be controlled by catalytic reactions on the surface of platinum impregnations.

\section{REFERENCES}

[1] V. E. Vigdergauz and V. A. Chanturia, "Alteration of IonMolecular Composition of Sulfide Ore Slurry Depending on the Development of Redox Processes in It," Mining Journal, No. 6, 2008, pp. 71-75.

[2] V. E. Vigdergauz, D. V. Makarov, I. V. Zorenko, E. V. Belogub, M. N. Maljarenko, E. A. Shrader and I. N. Kuznetsova, "Effect Exerted by Structural Features of Copper-Zinc Ores on Their Oxidation and Technological Properties," Journal of Mining Science, Vol. 44, No. 4, 2008, pp. 101-110.

[3] S. Suárez, H. M. Prichard, F. Velasco, P. C. Fisher and I. McDonald, "Alteration of Platinum-Group Minerals and Dispersion of Platinum-Group Elements during Progressive Weathering of the Aguablanca Ni-Cu Deposit, SW Spain," Mineralium Deposita, Vol. 45, No. 4, 2010, pp. 331- 350.

[4] D. A. Holwell and I. McDonald, "Distribution of PGE in the Platreef at Overysel, Northerm Bushveld Complex: A Combined PGM and LA-ICP-MS Study," Contrib Mineral Petrol, Vol. 154, No. 2, 2007, pp. 171-190. doi:10.1007/s00410-007-0185-9

[5] D. Hutchinson and I. McDonald, "Laser Ablation ICPMS Studu of Platinum-Group Elements in Sulphides from the Platreef at Turfspruit Norther Limb of the Bushveld Complex, South Africa," Miner Deposita, Vol. 43, No. 6, 2008, pp. 695-711. doi:10.1007/s00126-008-0190-6

[6] A. J. H. Newell, D. J. Bradshaw and P. J. Harris, "The Effect of Heavy Oxidation upon Flotation and Potential Remedies for Merensky Type Sulfides," International Journal of Mineral Processing, Vol. 19, 2006, pp. 675-686. 
[7] C. J. Moraza, N. Iglesias and I. Palencia, "Application of Sugar Foam to a Pyrite-Contaminated Soil," International Journal of Mineral Processing, Vol. 19, No. 5, 2006, pp. 399-406.

[8] V. T. Kalinnikov, V. N. Makarov, S. I. Mazuhina, D. V. Makarov and V. A. Masloboev, "The Study of Supergene Processes in the Tailings of Sulfide Copper-Nickel Ore," Chemistry for Sustainable Development, Vol. 13, No. 4, 2005, pp. 515-519.

[9] D. V. Makarov, V. N. Makarov, S. V. Drogobuzhskaja, A. A. Alkatseva, E. R. Farvazova and M. V. Tunina, "Envi- ronmental Pollution. The Content of $\mathrm{Ni}, \mathrm{Cu}, \mathrm{Co}, \mathrm{Fe}, \mathrm{MgO}$ in the Tailings of Pore Fluids of Copper-Nickel Ore, after Long-Term Storage," Environmental Geoscience, No. 2, 2006, pp. 135-142.

[10] D. A. Dodin, D. V. Lenchuk and V. M. Izoitko, "Technogenetics Deposits of Norilsk Region", International Symposium of Mineral Resources of Russia, St. Petersburg, 10 - 13 November 1993, pp. 10-12.

[11] A. T. Lebedev, "Mass Spectrometry in Organic Chemistry," Publishing House BINOM, Knowledge Laboratory, Moscow, 2003, p. 493. 